\title{
Direitos humanos, Religião e Política Por UM DESPERTAR DO ANSEIO ÉTICO
}

\author{
HUMAN RIGHTS, RELIGION AND POLITICS BY A \\ DESPERATION OF THE ETHICAL YEARNING
}

\section{Matheus Souza Gomes *}

\begin{abstract}
RESUMO
Chama a atenção desde meados da década de 1980 a crescente presença de representantes religiosos - especialmente os de denominações evangélicas - no meio político brasileiro. Tal fato instigou diversos autores brasileiros a pensarem na questão dos "fenômenos" de laicização e secularização em nosso contexto. Não focaremos aqui na complexidade em torno destas categorias, mas destacaremos o modo como elas se relacionam com o "avanço" da religião sobre o espaço público no Brasil. Além disto, analisaremos o desdobramento dessa relação conflituosa no que diz respeito à questão dos Direitos Humanos. Por fim, apresentaremos um possível caminho que as "religiões brasileiras" podem tomar para o avanço dos direitos das minorias no país, a partir das noções de moral e virtude dinamogência propostas por Durkheim.
\end{abstract}

Palavras-chave: Direitos Humanos. Religião. Política. Espaço público. Dinamogênese. Moral.

\begin{abstract}
Attention has been drawn since the mid-1980s to the growing presence of religious representatives - especially those of evangelical denominations - in the Brazilian political environment. This fact encouraged several Brazilian authors to think about the "phenomena" of secularization and secularization in our context. We will not focus here on the complexity surrounding these categories, but we will highlight how they relate to the "advancement" of religion over public space in Brazil. In addition, we will analyze the unfolding of this conflicting relationship with regard to the issue of Human Rights. Finally, we will present a possible path that "Brazilian religions" can take to advance the rights of minorities in the country, based on the notions of moral and virtue dynamism proposed by Durkheim.
\end{abstract}

Keywords: Human Rights. Religion. Policy. Public place. Dynamogenesis. Moral.

\footnotetext{
* Mestre em Ciências da Religião pela Pontifícia Universidade Católica de Minas Gerais. Bolsista CAPES. E-mail: matheusgomes1987@gmail.com.
} 


\section{INTRODUÇÃO}

Sobre a questão da relação entre religião e política no Brasil, a constante e crescente presença dos evangélicos ${ }^{1}$ (mais especificamente das denominações pentecostais e neopentecostais) nas instituições representativas do país é objeto de investigação de vários pesquisadores das Ciências Humanas e Sociais nas últimas duas décadas. Uma vasta literatura (FRESTON, 1993; MARIANO e PIERUCCI, 1992; MACHADO, 2007) foi e ainda é produzida em torno dessa presença evangélica no meio político brasileiro.

A trajetória dos evangélicos no meio político vem de longa data, mas ganhará notoriedade durante a década de 1980. Desde então esse grupo vem se destacando no período da "Nova República” brasileira, tendo papel importante, até mesmo, na eleição de presidentes da República. É claro que o protagonismo dos evangélicos na política está atrelado ao aumento considerável destes no meio social. O aumento de adeptos e o surgimento de novas denominações nos últimos trinta anos, contribuem com a elevação da representatividade evangélica nas principais instituições democráticas do país.

Juntamente com a ocupação de cargos políticos e públicos, os evangélicos trazem consigo seus próprios projetos que, muitas vezes, se orientam a partir das convicções religiosas das denominações representadas por esses indivíduos. Neste sentido, é interessante denotar a relação dos programas de representantes evangélicos com outras demandas da sociedade civil em geral. Partindo desse diálogo entre representatividade evangélica e necessidades da sociedade, o presente trabalho busca demonstrar de que modo a atuação de religiosos no espaço público interfere ou auxilia na ampliação e garantia dos Direitos Humanos no Brasil. Para tanto, Veremos que os fenômenos de laicização e secularização, caros à modernidade, não

\footnotetext{
${ }^{1}$ Toma-se como referência para este trabalho, a observação de Pierucci e Mariano acerca da categoria de evangélicos e a justificativa para utilizá-la como sinônimo de pentecostais e neopentecostais: "Diferentemente do que ocorre nos Estados Unidos, no Brasil o termo evangélico designa e recobre tanto as denominações protestantes históricas (Luterana, Presbiteriana, Metodista, Batista, Congregacional, Episcopal etc.), quanto as pentecostais (Assembleia de Deus, Congregação Cristã no Brasil, Evangelho Quadrangular, O Brasil para Cristo, Deus é Amor, Casa da Bênção, Nova Vida, Universal do Reino de Deus, Internacional da Graça de Deus etc.). Os pentecostais acrescentam às doutrinas protestantes básicas a crença na atualidade dos dons do Espírito Santo, dentre os quais sobressai a glossolalia, que ocorre quando o fiel fala "línguas estranhas", reproduzindo o episódio bíblico vivido pelos apóstolos cinquenta dias após a ressurreição de Cristo, no dia de Pentecostes" (MARIANO; PIERUCCI, 1992, p. 92).
} 
diminuíram a influência da religião no meio social. Mas, pelo contrário, ofereceram aos religiosos novas possibilidades de agir, ainda que a força destes tenha diminuído no sentido de orientar o sujeito e a sociedade como outrora fizeram com tanto vigor. Por fim, demonstraremos como as noções de moral e virtude dinamogênica propostas por Emile Durkheim podem auxiliar as religiões no Brasil a se engajarem na luta pela defesa e consolidação dos direitos das minorias.

\section{Laicidade, secularização e religião}

Apontamos, anteriormente, que nos propomos à tarefa de mostrar de que modo a laicização e a secularização, categorias muito utilizadas para compreender as transformações provocadas na sociedade ocidental pelo fenômeno da modernidade, se relacionam, ainda que pareça absurdo, com a religião no Brasil. É uma proposta audaciosa, admitimos, devido à alta complexidade que se apresenta em torno da discussão sobre as categorias já citadas no meio acadêmico. Não pretendemos adentrar neste debate, ainda que ele se apresente como essencial para compreender as características das sociedades e dos sujeitos na modernidade. Mas, não podemos avançar na relação destes fenômenos com o campo religioso sem antes delimitarmos o modo como serão abordados nessa breve reflexão. Sobre as categorias já citadas, entende-se, que apesar de sua polissemia, em certos sentidos, elas se aproximam. É preciso reconhecer que o conceito de laicidade possuí suas limitações e se insere dentro de um contexto de emancipação da esfera pública (Estado):

[...] dos poderes eclesiásticos e de toda referência e legitimação religiosa, enquanto que a secularização, recobre processos de múltiplos níveis, referindo-se a distintos fenômenos sociais e culturais e instituições jurídicas e políticas, nos quais se verifica a redução da presença e influência das organizações, crenças e práticas religiosas. (MARIANO, 2011, p. 244).

Em síntese, a laicidade diz respeito a um fenômeno relativamente recente na história da sociedade ocidental, enquanto que a secularização possuí uma duração mais longa na trajetória do Ocidente, avançando ou retrocedendo de acordo com as transformações que ocorrem no meio cultural, econômico, político e social. Ainda sim, algo aproxima esses dois fenômenos, especialmente no período da modernidade: a transformação que ambos proporcionaram ao campo religioso. A modernidade do 
Ocidente $^{2}$, que iniciou sua trajetória em fins do século XVIII e ainda passa por diversas metamorfoses, se dispôs da secularização e laicização das instâncias estatais no intuito de reduzir a influência da religião sobre os rumos do Estado. Sendo assim, o objetivo era de limitar o campo religioso à esfera privada, fato que não ocorreu.

O que testemunhamos é que a incompatibilidade entre modernidade e religião como um caminho natural da secularização e da laicidade não se consolidou (SOUZA, 2015, p. 73). Percebe-se, ao contrário, uma acomodação por parte da religião dentro da sociedade ocidental secularizada, no sentido, até mesmo, de garantir a consolidação desta. Isto é visto, por exemplo, através da atuação dos grupos evangélicos brasileiros durante a Assembleia Constituinte formada em 1986. Temendo um estreitamento na relação entre o Estado brasileiro e a Igreja Católica, os congressistas evangélicos se engajaram para garantirem que a Carta Magna contemplasse valores considerados secularistas, como a defesa do pluralismo religioso, da liberdade de culto e da laicidade.

Intriga-nos o fato de que do mesmo modo que defenderam questões que, a princípio, pertencem ao espaço público secularizado, os evangélicos trazem consigo uma série de "valores morais" particulares de suas crenças religiosas para o debate político, visando, segundo eles, a garantia dos bons costumes, a defesa da família tradicional brasileira e os valores cristãos. Junto a eles, grupos católicos também seguem o mesmo caminho e, assim, vemos a presença cada vez maior de grupos religiosos no espaço e debates políticos. A questão não é a presença destes no espaço público brasileiro, mas sim o que seus projetos defendem e a consequência deles para a sociedade. É o que debateremos no próximo tópico.

\section{Direitos Humanos e Religião no Brasil}

É cada vez mais notória a força que os grupos religiosos possuem no meio político brasileiro. Essa expressividade fica ainda mais evidente com as polêmicas envolvendo os diversos representantes das instituições religiosas, que ingressam em cargos representativos nas mais diversas instâncias, no que tange ao debate em torno da ampliação e consolidação de direitos de grupos minoritários da sociedade

\footnotetext{
${ }^{2}$ Segundo Hans Joas (2015, p. 227), a modernidade se caracteriza pelo crescimento econômico e pelo progresso científico da sociedade ocidental.
}

INTERAÇõES, Belo Horizonte, Brasil, v. 13. n. 23, p.222-230, jan./jul.2018

ISSN 1983-2478 
brasileira. Vale lembrar que tais garantias buscam proteger e reconhecer as demandas dessas minorias, no sentido de que tenham assegurada a integridade de suas vidas, suas particularidades e de sua diversidade, seja ela de caráter cultural, de gênero, de etnia ou, até mesmo, religiosa.

Não é difícil encontrarmos exemplos de projetos e representantes políticos influenciados por questões religiosas se posicionando contra o avanço de uma série de ações concretas que buscam garantir a ampliação dos Direitos Humanos, especialmente dos grupos minoritários. Para melhor ilustrarmos, citamos o caso do debate envolvendo o Plano Nacional de Educação, mais especificamente o tópico que colocava em pauta a questão da necessidade de ampliar nas escolas brasileiras o debate em torno das questões de desigualdade de gênero e orientação sexual. Como se viu, políticos católicos e evangélicos mobilizaram-se e buscaram apoio em parte da sociedade civil com o objetivo de barrar essa proposta, pois, segundo eles, a parte do PNE que trataria do que denominaram pejorativamente de "ideologia de gênero", era uma ameaça à família brasileira (SOUZA, 2015, p. 81). A mobilização surtiu efeito:

A retirada do substitutivo ao artigo $2^{\circ}$ do PLC, que incluí a igualdade de gênero como diretriz do PNE, foi celebrada por grupos católicos e evangélicos e por parlamentares da Frente Parlamentar Evangélica (FPE), que festejaram e se apresentaram como vitoriosos guardiões da família brasileira, como defensores da família natural, como protagonistas na luta contra as investidas ameaçadoras de feministas e LGBTT's. (SOUZA, 2015, p. 84).

São as mulheres, representadas pelas feministas, e os grupos LGBTT's os principais alvos de ataque por parte de parlamentares religiosos. Essa ofensiva contra grupos minoritários, com base em preceitos religiosos, representa uma ameaça ao avanço e à consolidação dos Direitos Humanos no Brasil. Falta, talvez, como afirmou Leonardo Sakamoto em texto de seu blog, a construção de uma tradição que seja capaz de mostrar aos cidadãos brasileiros a necessidade pelo respeito aos direitos humanos sem o medo da punição por desrespeito a estes. O ideal, segundo o jornalista e cientista político, seria o despertar de uma "consciência de que a sociedade deve levar em conta a vontade da maioria desde que respeitada a dignidade das minorias" (SAKAMOTO, 2016).

Precisamos ainda lembrar que a atuação de católicos e evangélicos conservadores possuí ressonância no meio social. Existe uma significativa parcela da 
sociedade civil que apoia as atitudes e os discursos destes políticos. Do mesmo modo, é preciso também dizer, que nos meios católico e evangélico também existem sujeitos que não concordam com os discursos e propostas feitas por seus ditos "representantes" no Congresso Nacional ou, até mesmo, seus líderes religiosos. É nessa dissidência do dado religioso, que reside a "esperança" de vermos as religiões de maiores adeptos no Brasil a empreenderem na construção dessa cultura de respeito aos Direitos Humanos. Mas qual seria o caminho?

\section{Moral e dinamogênese no despertar de um anseio ético}

Podemos pensar nos Direitos Humanos como um grande conjunto de regras morais na perspectiva durkheimiana. Ao refletirmos sobre a moral na ótica do sociólogo francês para a questão que diz respeito ao papel da religião na ampliação e consolidação dos direitos fundamentais, é possível dizermos que apesar da moral particular que orienta as tradições religiosas nem sempre ser de caráter "inclusivo", esta não se sobrepõe à regra geral que orienta a sociedade. Neste sentido, temos que a regra moral que guia a sociedade, em geral, é baseada nos Direitos Humanos. Sendo assim, é essa moral "maior" que deve coordenar as ações dos indivíduos, mas sem que eles necessariamente abram mão de aspectos de sua moral particular e desde que ela não seja “agressiva” à regra geral.

Mas, seria possível para as religiões, no caso brasileiro, tornarem-se lugar para formação de consciências e sujeitos capazes de conciliar uma moral particular mais simpática aos direitos humanos e às demandas das minorias. A questão se aproxima de outro questionamento feito por Adilson Schultz (2015, p.111-112) do seguinte modo: existe a possiblidade de forjar sujeitos éticos na tensão entre a reivindicação universalizante dos Direitos Humanos e o caráter particular do dado religioso? Responder tais inquietações não é tão simples. A princípio, é possível dizer que sim, o dado religioso possibilita a formação de sujeitos éticos em consonância com os Direitos Humanos. Mas, como? Levando-se em conta a perspectiva de Durkheim sobre o "poder" que a moral exerce nos indivíduos e na virtude dinamogência identificada pelo sociólogo nas religiões, podemos nos arriscar em responder à pergunta acima com certo otimismo. É justamente na perspectiva durkheimiana 
acerca da origem social da religião e de sua "propriedade" dinamogênica que essa tarefa de despertar um anseio ético nos indivíduos parece possível.

Segundo Raquel Weiss (2007, p.21-22) a ação moral, para Durkheim, é aquela que se volta para um fim que transcende os indivíduos, que seja qualitativamente superior a eles. A moral são regras que possuem existência própria e que se impõem sobre a vontade do indivíduo. Por isto, a moral se apresenta para o sujeito como um dever de agir de acordo com ela. E esta ação moral muitas vezes requer abdicação dos indivíduos em nome dos preceitos que consideramos moralmente bons. Em síntese, a moral nos impele de atuar de modo cooperativo com aquilo que garante um bem maior e a proteção da coletividade. Neste sentido, os Direitos Humanos podem ser considerados a principal regra moral da modernidade.

Sobre a virtude dinamogênica, tão cara à religião também pode influenciar o caráter particular do dado religioso no sentido de promover a formação destes sujeitos éticos. Essa propriedade dinamogênica da religião é o que eleva o fluxo de energia e faz os sujeitos se sentirem mais fortes enquanto se alimentam dessa força. $\mathrm{E}$ essa força é capaz elevar os indivíduos acima deles mesmos, os fazendo viver uma vida mais elevada e intensa (DURKHEIM, 2012, p. 31).

Se a moral, representada, por exemplo, na modernidade pelos Direitos Humanos, é capaz de formar indivíduos preocupados em proteger e garantir a sobrevivência da diversidade em geral, a religião também é capaz de promover esta transformação moral nos sujeitos religiosos. E essa mudança vai ao sentido de promover nestes um "despertar" que os eleve acima deles mesmos para que comunguem de uma consciência mais universal (coletiva), que se volta para o outro e busca lutar para que este tenha seus direitos e a própria vida protegidos.

Essas brechas na consciência do dado religioso podem despertar mesmo que este não atue de modo direto para isto. Ainda que as instituições religiosas se oponham ao avanço dos Direitos Humanos, elas não podem evitar que seus frequentadores despertem este sentimento de justiça, chamado também de anseio ético. 


\section{CONSIDERAÇÕES FINAIS}

Anseio ético. É essa categoria, que segundo Alan Touraine e Rita Segato, citados por Schultz (2015, p. 114-115), se apresenta para as sociedades no intuito de "superar" a esfera de domínio atual, a saber, a lógica financista, e a consolidação dos Direitos fundamentais. Segundo Touraine, a saída para deter a crise produzida pelo sistema financista seria reconstruí lógicas fortes ligadas aos Direitos Humanos. Para Segato, a consolidação de tais direitos, passa fundamentalmente pela despertar de consciências dissidentes, capazes lutarem pela justiça. É o que a autora denomina de anseio ético.

Através deste que seria possível o alargamento de direitos fundamentais, inclusive para dentro de culturas particulares, como por exemplo, as religiosas. As religiões, apesar de seu caráter particular muitas vezes invalidar os Direitos Humanos, ao assumirem como movimentos sociais, na perspectiva de Touraine, têm potência e capacidade de forjarem o anseio ético. Assim como os Direitos Humanos que transcende os indivíduos e os eleva acima do costume social, a religião, na concepção de Durkheim, é impelida dessa virtude dinamogênica, que tonifica e possibilita às consciências dos sujeitos se tornarem uma consciência coletiva e superior à organização social. É justamente a partir dessa origem social da religião, que ela pode constituir o anseio ético. E a partir dele, agir sobre os indivíduos para consolidar os direitos fundamentais.

Precisa-se ainda fazer uma pequena observação: apesar dessa perspectiva positiva de Touraine, Segato e Schultz que permite afirmar sobre a capacidade do dado religioso, apesar de suas particularidades, de formar sujeitos éticos, o que se vê ainda hoje, tanto em território nacional como em outros locais do mundo, são as instituições religiosas em uma luta frequente contra o avanço e consolidação dos Direitos Humanos. Este caráter paradoxal demonstra a ambivalência do dado religioso, e o desafio que se apresenta para as religiões na modernidade: encontrar um caminho onde seja possível manter suas particularidades, sem que estas ataquem, desrespeitem ou minem os direitos fundamentais de outros grupos sociais. 


\section{REFERÊNCIAS}

DURKHEIM, Émlie. O problema religioso e a dualidade da natureza humana. Debates do NER, Porto Alegre, v. 13, n. 22, p. 27-61, 2012.

JOAS, Hans. A secularização conduz à decadência moral. In: SOCIOLOGIASUFRGS, Porto Alegre, v. 17, n. 39, p. 224-246, mai./ago. 2015.

MACHADO. Maria das Dores Campos. A magia e a ética no pentecostalismo brasileiro. Estudos de religião, São Paulo, ano 21, n. 33, p. 12-26, jul/dez 2007.

MARIANO, Ricardo; PIERUCCI, Antônio Flávio. O envolvimento dos pentecostais na eleição de Collor. Novos Estudos, n. 4, nov. 1992. p. 92-106.

MARIANO, Ricardo. Laicidade à brasileira: Católicos, pentecostais e laicos em disputa na esfera pública. Civitas, Porto Alegre, v. 11, n. 2, 2011, p. 238-258.

SAKAMOTO, Leonardo. A placa diz que a cidade é de Jesus. Mas ele me disse que é intriga.

Disponível em: <blogdosakamoto.blogsfera.uol.com.br/2016/o6/19/a-placa-diz-quea-cidade-e-de-jesus-mas-ele-me-disse-que-isso-e-intriga/> . Acesso em: 19 jun. 2016.

SCHULTZ, Adilson. O aspecto universal dos Direitos Humanos em tensão criativa com a dimensão relativa da Religião. In: ROSSI, Luiz Alexandre, JUNQUEIRA, Sérgio. (Org.). Religião, Direitos Humanos e Laicidade. São Paulo: Fonte Editorial, 2015, v. 1, p. 111-124.

WEISS, Raquel. A teoria moral de Émile Dukheim. In: XIII Congresso da Sociedade Brasileira de Sociologia, 2007, Recife. Anais do XIII Encontro da SBS. 